\title{
PENDIDIKAN PELATIHAN KETERAMPILAN KERJA KEWIRASWASTAAN DI SMK MELALUI TRAINING CLASS MOTIVATION
}

\author{
Yuyun Yuniarsih \\ Universitas Sangga Buana Bandung \\ Pos-el: yuyunyuniarsih79@gmail.com
}

\begin{abstract}
ABSTRAK
Pendidikan pelatihan keterampilan kerja Kewiraswastaan di SMK melalui training class motivation, dapat dilakukan di sekolah menengah kejuruan hal ini untuk memotivasi siswa agar dapat hidup mandiri di tengah masyarakat, tujuan penelitian ini untuk mengetahui tingkat keterampilan siswa dalam membuat karya yang dapat berguna untuk kehidupannya di tengah masyarakat. Tujuan dari kegiatan ini agar siswa memiliki jiwa kewirausahaan, agar siswa disiplin terhadap waktu dan dapat menggunakan waktu secara baik. Tujuan yang ke dua melalui keterampilan yang dimiliki oleh siswa maka dapat menjadi modal awal atau bekal hidup ketika kelak sudah tidak bekerja lagi di instansi atau lembaga. Tetapi tidak menutup kemungkinan bagi mereka yang sudah memiliki jiwa wiraswasta dapat melaksanakan atau mengamalkannya, kelas yang diberi motivasi adalah kelas yang anak anaknya merasa tidak percaya diri di suatu sekolah. Metode penelitian tindakan dimana metode penelitian tindakan ini dapat menggunakan data kualitatif dan data kuantitatif yang dapat dipaparkan, hasil dari penelitian ini siswa memiliki keterampilan, yang di awali rasa percaya diri yang timbul, memiliki disiplin yang tinggi, serius dalam menggeluti pekerjaan. itu melalui training class motivation dapat membentuk jiwa wirausaha pada diri siswa di kelas XII SMK BB, mulai dari awal atau dasar sebagai pondasi ke depannya, hal ini pun tetap harus dilakukan kontinu tidak cukup sekali saja. Ini merupakan tanggung jawab bersama lapisan masyarakat Indonesia agar SMK tidak menjadi penyumbang pengangguran terbesar.
\end{abstract}

Kata Kunci : membangun, jiwa, kewirausahaan, era modern

\begin{abstract}
Vocational training in entrepreneurship work skills in vocational training through class motivation training, can be done in vocational high schools, this is to motivate students to be able to live independently in the community, the purpose of this study is to determine the level of student skills in making work that can be useful for their lives in the community. The purpose of this activity is for students to have an entrepreneurial spirit, so that students are disciplined with time and can use their time well. The second goal is through the skills possessed by students, it can be an initial capital or provision of life when one does not work anymore in an agency or institution. But it does not rule out the possibility for those who already have an entrepreneurial spirit to carry out or practice it, the motivated class is a class whose children feel insecure in a school. The action research method where this action research method can use qualitative data and quantitative data that can explained, the results of this study students have the skills, which begin the self-confidence that arises, have a high discipline, serious in the work. that through class motivation training can shape the entrepreneurial spirit of students in class XII Vocational High School, starting from the beginning or the foundation as a foundation in the future, this must still be done continuously not enough once. This is a shared responsibility of the Indonesian people so that vocational schools do not become the biggest contributors to unemployment.
\end{abstract}

Keywords: building, soul, entrepreneurship, modern era 


\section{PENDAHULUAN}

Masalah ketidakseimbangan antara angkatan kerja dengan kesempatan kerja menjadi masalah dalam lingkungan masyarakat dan dewasa ini masih tetap menjadi topik pembicaraan penting. Kondisi seperti ini akan mendorong timbulnya permasalahan baru yang lebih kompleks dan rawan apabila tidak segera ditangani secara serius dan profesional. Oleh karena itu pendidikan penanaman jiwa kewirausahaan di kalangan siswa SMK perlu digalakan.

SMK menjadi sasaran utama untuk dapat mengembangkan pola pendidikan yang dapat membentuk jiwa atau karakter kewirausahaan.

Menurut Sardiman AM (2011) menyatakan bahwa motivasi adalah serangkaian usaha untuk menyediakan kondisi-kondisi tertentu sehingga seseorang mau dan ingin melakukan sesuatu, dan bila ia tidak suka maka akan berusaha untuk meniadakan dan mengelakan perasaan tidak suka itu. Motivasi dapat dikatakan sebagai penggerak dalam diri siswa yang menimbulkan kegiatan belajar yang menjamin kelangsungan dari kegiatan belajar dan memberikan arah pada kegiatan belajar sehingga tujuan yang dikehendaki oleh subyek belajar itu dapat tercapai.

Sedangkan Mohammad Asrori (2009) mendefinisikan motivasi belajar sebagai dorongan yang timbul pada diri seseorang, secara disadari atau tidak untuk melakukan suatu tindakan dengan tujuan tertentu atau usaha-usaha yang dapat menyebabkan seseorang atau kelompok orang tertentu tergerak melakukan sesuatu karena ingin mencapai tujuan yang ingin dicapai. Keberhasilan belajar siswa dalam proses pembelajaran, sangat dipengaruhi oleh motivasi yang ada pada dirinya.
Indikator kualitas pembelajaran salah satunya adalah adanya motivasi belajar yang tinggi dari para siswa.

Salah satu jenis pendidikan di Indonesia adalah pendidikan kejuruan. Menurut Undang-Undang Sisdiknas bahwa "Pendidikan Kejuruan merupakan pendidikan menengah yang mempersiapkan peserta didik terutama untuk bekerja dalam bidang tertentu." SMK tidak hanya dapat menyalurkan tenaga kerja tetapi harus dapat membekali siswa lulusannya jiwa wirausaha, sebab apabila mereka tidak dapat bekerja di perusahaan dapat menjadi wirausaha.

Mengenai pendidikan kejuruan dijabarkan lebih spesifik dalam Peraturan Pemerintah Nomor 29 Tahun 1990 tentang Pendidikan Menengah pasal 1 ayat 3 yaitu: "Pendidikan Menengah Kejuruan adalah pendidikan pada jenjang pendidikan menengah yang mengutamakan pengembangan kemampuan siswa untuk melaksanakan jenis pekerjaan tertentu".Pada ayat 2 disebutkan bahwa pendidikan menengah kejuruan mengutamakan kesiapan siswa untuk memasuki lapangan kerja serta mengembangkan sikap profesional.

\section{METODE PENELITIAN}

Penelitian yang dilakukan menggunakan Penelitian Tindakan Kelas pada kelas XII yang berjumlah 42 orang jurusan Akuntansi SMK BB2 dengan menggunakan model Stephen Kemmis dan Robbin MC.Taggart yang dapat dilihat pada bagan berikut ini. 


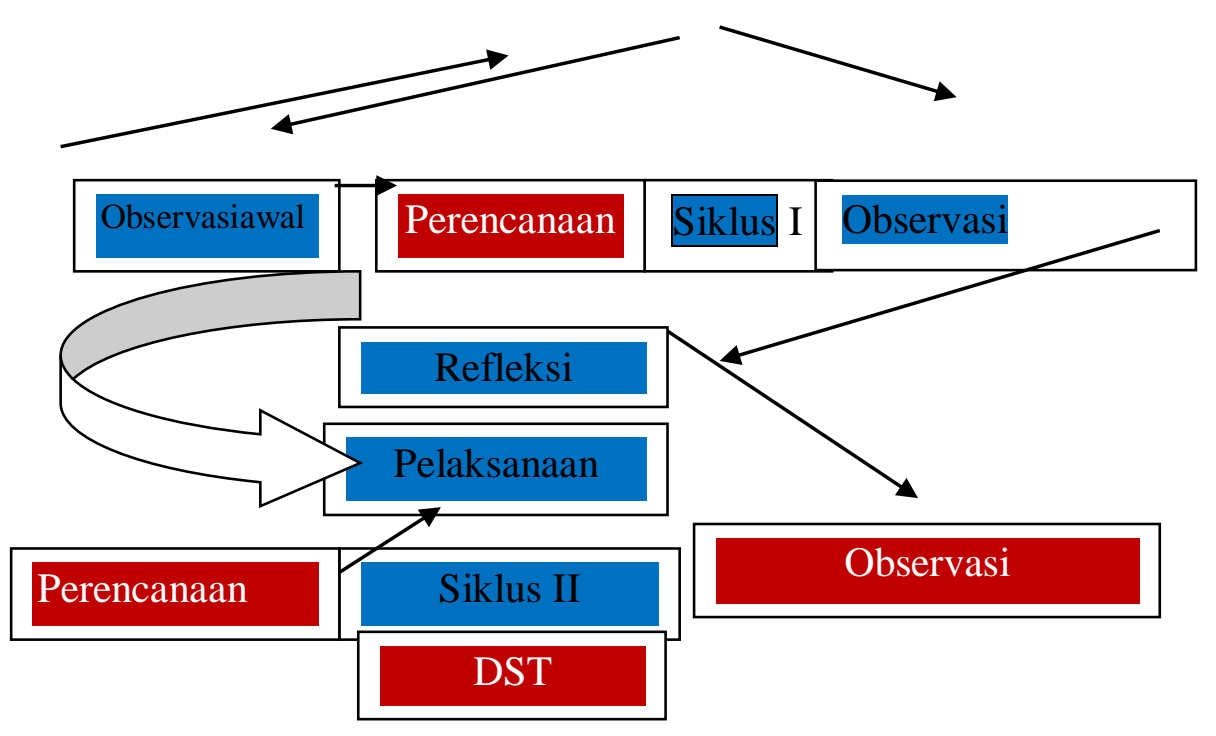

GAMBAR 1.1. MODIFIKASI SIKLUS PTK Sumber: Arikunto, S. (1997)

Prosedur pelaksanaan penelitian tindakan kelas dilakukan melalui tahaptahap:

1. Tahap Observasi Awal.

2. Tahap Perencanaan

3. Tahap Pelaksanaan

4. Tahap Observasi

5. Tahap Refleksi

Analisis data merupakan proses keberlanjutan yang membutuhkan refleksi terus menerus terhadap data, mengajukan pertanyaan-pertanyaan analitis, dan menulis catatan singkat sepanjang penelitian. Menurut (Stake, 1995 dikutip Creswell, 2010) analisis data melibatkan pengumpulan data yang terbuka, yang didasarkan pada pertanyaan-pertanyaan umum dan analisis informasi dari para partisipan.

Tabel1.1 Klasifikasi Kategori Nilai Dan Persentase

\begin{tabular}{|l|l|l|}
\hline KRITERIA & NILAI & KATEGORI \\
\hline Baik sekali & $91-100$ & $\begin{array}{l}\text { Hasil belajar } \\
\text { baik sekali }\end{array}$ \\
\hline Baik & $80-89$ & $\begin{array}{l}\text { Hasil belajar } \\
\text { baik }\end{array}$ \\
\hline Cukup & $70-79$ & $\begin{array}{l}\text { Hasil belajar } \\
\text { cukup }\end{array}$ \\
\hline Kurang & $60-69$ & $\begin{array}{l}\text { Hasil belajar } \\
\text { kurang }\end{array}$ \\
\hline $\begin{array}{l}\text { Kurang } \\
\text { Sekali }\end{array}$ & $\leq 50$ & $\begin{array}{l}\text { Hasil belajar } \\
\text { kurang sekali }\end{array}$ \\
\hline \multicolumn{2}{|c|}{ Sumber: RPP SMK BB2 }
\end{tabular}

Pengujian Hifotesis, melalui training class motivation dapat membentuk jiwa wirausaha pada diri siswa di kelas XII SMK BB.

\section{HASIL DAN PEMBAHASAN}

a. Tahap Observasi Awal

Tahap Observasi Awal dari 42 siswa SMK yang belum mengikuti kelas kewirausahaan siswa tidak memiliki keinginan untuk belajar berwirausaha, sehingga dapat dikategorikan peminatan untuk menjadi wirausaha adalah kurang sekitar $60 \%$ siswa tidak mau berwirausaha.

b. Tahap Kedua

Tahap Kedua diadakan perencanaan melaksanakan kelas motivasi atau guru sebagai instruktur memberikan motivasi atau pelatihan berwirausaha selama 1 minggu kepada siswa.

c. Tahap Pelaksanaan

Pada tahap pelaksanaan siswa mengikuti arahan instruktur di dalam kelas selama 1 minggu perhari 3 jam pelajaran, siswa di beri pengarahan dan motivasi mengenai wiraswasta yang berasal dari bahasa Sanskerta, dari 3 suku kata, wira utama, luhur, teladan perkasa dan berani, swa, artinya sendiri, sta berdiri, jadi wiraswasta itu upaya 
yang dilakukan oleh seseorang dengan kemampuan sendiri untuk menjadi yang utama, luhur, teladan perkasa untuk mencapai tujuan. Lalu siswa setelah dimotivasi oleh instruktur di beri sebuah produk yang harus dipasarkan dalam jangka waktu 1 minggu. Tetapi mereka pun bisa belajar membuat produk yang bisa di pasarkan.

d. Tahap Observasi

Pada siklus 1 dan II sama, ketika di observasi 42 siswa aktif dan mau memasarkan produk dan mereka semangat, karena di beri pelatihan di kelas motivasi, mereka tidak merasa malu di sinilah timbul jiwa wirausahanya.

e. Tahap Refleksi

Pada tahap refleksi siswa di masukan dalam kelas motivasi lalu di beri pertanyaan apakah ada kendala, tetapi dari 42 siswa tersebut 3 siswa yang tidak mengikuti karena sakit.

Tabel 1.2 Klasifikasi Kategori Nilai dan Persentase

\begin{tabular}{|c|c|c|}
\hline KRITERIA & NILAI & Jumlah \\
\hline Baik sekali & $91-100$ & 20 \\
\hline Baik & $80-89$ & 17 \\
\hline Cukup & $70-79$ & 2 \\
\hline Kurang & $60-69$ & \\
\hline $\begin{array}{c}\text { Kurang } \\
\text { Sekali }\end{array}$ & $\leq 50$ & \\
\hline $\begin{array}{c}\text { Tidak } \\
\text { Mengikuti }\end{array}$ & & 3 \\
\hline
\end{tabular}

Dari hasil evaluasi pada kelas kewirausahaan minat mereka terhadap wirausaha baik dan diadakan terst tentang dampak positif dari berwirausaha melalui soal pertanyaan kewirausahaan siswa yang masuk kategori 1 sebanyak 20 orang, yang masuk kategori 2 sebanyak 15 orang, kateori 3 sebanyak 2 orang.

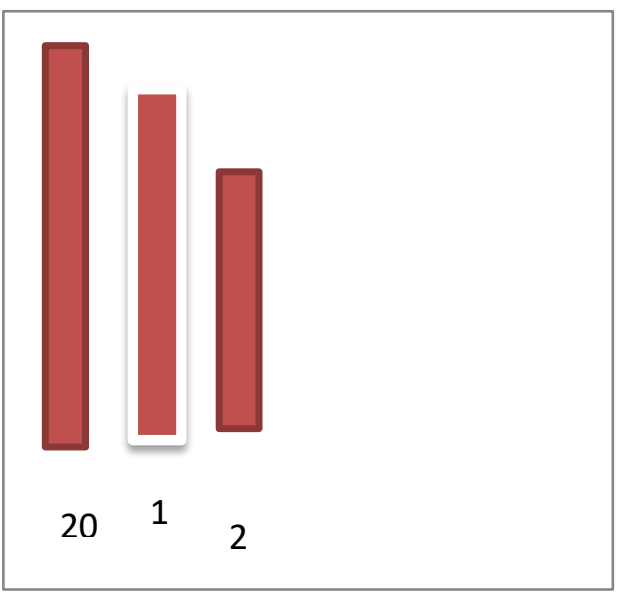

Gambar: 1.2

Training Class Motivation

Dari hasil evaluasi pada kelas yang di beri motivasi sebanyak 20 siswa nilai di kategorikan baik sekali pada hasil tes wirausaha dengan penjualan produk dan hasil tes atau ulangan, minat mereka terhadap wirausaha. Dan sebanyak 15 orang kategori baik pada siklus I, mereka tidak memiliki sifat minder atau malu untuk memulai wirausaha, sedangkan kategori 3 sebanyak 2 orang, mereka kurang maksimal dalam memasarkan karena sakit dan untuk 3 orang tidak masuk kategori karena tidak mengikuti kegiatan disebabkan sakit.

\section{PENUTUP}

Membentuk jiwa wirausaha atau kewiraswastaan memang tidak mudah, tetapi hal yang dasar dapat dilakukan pada saat siswa berada di sekolah SMK, karena mereka memilih SMK agar kelak dapat bekerja di perusahaan oleh karena itu melalui training class motivation dapat membentuk jiwa wirausaha pada diri siswa di kelas XII SMK BB, mulai dari awal atau dasar sebagai pondasi ke depannya, hal ini pun tetap harus dilakukan kontinu tidak cukup sekali saja. Ini merupakan tanggung jawab bersama lapisan masyarakat Indonesia agar SMK tidak menjadi penyumbang pengangguran terbesar. 


\section{DAFTAR PUSTAKA}

Asrori, Mohammad. (2009). Psikologi Pembelajaran. Bandung: Wacana Prima.

Arikunto, Suharsimi. (1997). Prosedur Penelitian Suatu Pendekatan Praktek. Jakarta: Rineka Cipta.

Creswell, Jhon. W. (2010). Research Design. Pendekatan Kualitatif, Kuantitatif, dan Mixed. Yogyakarta: Pustaka Pelajar.

Sardiman AM. (2011). Interaksi dan Motivasi Belajar Mengajar. Jakarta : Raja Grafindo Persada.

Peraturan Pemerintah Nomor 29 Tahun 1990 tentang Pendidikan Menengah pasal 1 ayat 